\title{
Risk of High Systolic Blood Pressure among the Air Crew in Bangladesh Air Force
}

\author{
Rahman $\mathrm{MM}^{1}$, Wahab $\mathrm{MA}^{2}$, Hossain $\mathrm{MZ}^{3}$, Yasin $\mathrm{MM}^{4}$ Quddus NKBG 5
}

DOI: https://doi.org/10.3329/jafmc.v17i1.56719

\begin{abstract}
Introduction: Military flight circumstances have been shown to affect Blood Pressure levels. Hypertension is the most severe threat that relates to myocardial infarction, stroke and kidney failure. Exposure to regular flight environment has been shown to Individuals Blood Pressure levels.
\end{abstract}

Objective: To find out the factors associate to presentation of hypertension in air crew in Bangladesh Air force.

Materials and Methods: It was a cross-sectional observational study was conducted among 100 Air Force' pilots of Bangladesh. Data were sort out from medical record files. Participants filled in a survey about demographics, lifestyle factors and dietary habits. Arterial Blood Pressure (BP) was also measured. Multivariate linear regression was implemented.

Results: Two patients had history of hypertension among them $2(100.0 \%)$ in high systolic blood pressure. Which was statistically significant $(p<0.05)$ between normal and high BP. Patients having age ( $\geq 40$ years) $2.6(95 \% \mathrm{Cl} 1.1 \%$ to $6.1 \%)$ times the risk for systolic blood pressure. patients having age ( $\geq 30$ years) 2.5 ( $95 \%$ $\mathrm{Cl} 0.3 \%$ to $22.4 \%$ ) times the risk for systolic blood pressure. Patients having history of hypertension $1.7(95 \% \mathrm{Cl} 0.01 \%$ to $46.3 \%$ ) times the risk for systolic blood pressure. Patients having Pulse (>80 beats per minute) $3.5(95 \% \mathrm{Cl} 0.2 \%$ to $52.8 \%)$ times the risk for systolic blood pressure. In multivariate analysis, age, history of hypertension and pulse were not statistically significant.

Conclusion: BP value of most of the air crew in Bangladesh Air Force' were within normal range. Few of BP standards have been reported in the study history of hypertension they have moreover family history of HTN. Contrastingly, there were some overweight and fast food eating while few reported not exercising.

Key-words: Hypertension (HTN), BAF Air Crew, Blood presure.

\section{Introduction}

Upraised blood pressure levels (BP) persist to comprise one of the most important public health problems worldwide ${ }^{1}$. Hypertension is among the largest part severe risk factors that relate to myocardial infarction, stroke and kidney failure ${ }^{1}$. Hypertension, also known as high blood pressure, is the "silent killer" and may lead to more severe conditions if held in reserve unmanaged ${ }^{2}$. As with all cardiovascular situations in aircrew, the aero-medical risk assessment extends well beyond the usual clinical risk assessment. The aero-medical significance vs. clinical significance of any CHD identification will be determined by the potential physiological consequences of the underlying pathology in the aviation environment ${ }^{3}$.

Military flight conditions have been shown to circumstances blood pressure levels. During flight, cabin pressure is correspondent to an altitude of 1524-2438 meters (reduced oxygen (15\%) and concentrated some amount of atmosphere pressure $)^{4}$. Under these conditions, blood pressure has been found to increase in known hypertensives ${ }^{5}$. However, these environment differ from fighter jets, where anti-G Suited Pilots having extraordinary training to counteract effects of $g$-forces from increased velocity, deceleration and flight maneuvers. Those Pilot are thought to having a kind of trend of Blood pressure levels and hypertension like that of others population. It was known that for that of jobs specific burden, BP levels should stand lower. But earlier studies showed that blood pressure don't have significant change over time ${ }^{6-7}$.

\section{Materials and Methods}

This is a cross sectional type of observational study. Data were collected following crew of Bangladeshi Air Force from the Military Hospital. Among 100 air-force pilots who were flying Jet aircrafts were randomly selected from the respondent of active fighter jet pilots. Participants aged between 25 to 55 years old. All participants were conversant about the aim of the study and signed an inform consent proceeding to taking part in the study, while they were convinced about their darkness and privacy. BAF crew's filled in a questionnaire regarding their exercise information, dietary habits and lifestyle, for epidemiological data studies some participants were requested to attend a military hospital for five consecutive weeks. Each week, three blood pressure dimensions took place using a mercury BP machine. Measurements of the first visit were kept out of account. But all other investigations were examined and the average and stander deviation were analyzed. Respondents were informed not to smoke at least 20 minutes and not to consume caffeinated beverages at least 60 minutes before Blood Pressure measurements. History was shown also earlier, we

1. Lt Col Md Masudur Rahman, MBBS, DAve Medicine, MPH, Classified Specialist in Aerospace Medicine, BAF Base Bashar (E-mail: masud8174@yahoo.com) 2. Lt Col Md Abdul Wahab, MBBS, MD, Associate Professor Biochemistry, AFMC 3. Lt Col Md Zakir Hossain, MBBS, FCPS, MCPS, DLO, Classified Specialist in ENT, Central Medical Board, BAF 4. Lt Col Md Muaz Yasin, AMC, Graded Specialist in Medicine, BAF Base Bashar 5. Dr Nur Kawser Binte Golam Quddus, MBBS, DMU, Consultant Sonologist, Nirapod Diagnostic, Manikdi, Dhaka Cantonment. 
have no information regarding medications taken regularly, normotension was classified according to hypertension guidelines as optimal blood pressure, normal blood pressure \& high normal blood pressure, while hypertension was evaluated as blood pressure $>140 \mathrm{~mm} \mathrm{Hg}$.

\section{Results}

Seventy patients belonged to age $<40$ years among them $67(95.7 \%)$ in normal systolic blood pressure and $3(4.3 \%)$ in high systolic blood pressure. Fifty three patients were found pulse $60-80$ beats per minute among them 52(98.1\%) in normal systolic blood pressure and $1(1.9 \%)$ in high systolic blood pressure. Which were statistically significant $(p<0.05)$ between two groups (Table-I). Sixty five patients were inappropriate exercise among them 59(90.8\%) in normal systolic blood pressure and 6(9.2\%) in high systolic blood pressure. Fifty five patients were eating fast food 1-2 times/week among them 51(92.7\%) in normal systolic blood pressure and 4(7.3\%) in high systolic blood pressure. Fifty nine patients had normal BMI among them 55(93.2\%) in normal systolic blood pressure and $4(6.8 \%)$ in high systolic blood pressure. The difference were not statistically significant $(p>0.05)$ between two groups (Table-II). Two patients had history of hypertension among them 2(100.0\%) in high systolic blood pressure. Which was statistically significant $(p<0.05)$ between two groups (Table-III). Patients having age ( $\geq 30$ years) $2.5(95 \% \mathrm{Cl} 0.2 \%$ to $22.4 \%)$ times the risk for systolic blood pressure. Patients having history of hypertension 1.7 (95\% Cl $0.01 \%$ to $46.3 \%$ ) times the risk for systolic blood pressure. Patients having Pulse ( $>80$ beats per minute) 3.5 (95\% $\mathrm{Cl} 0.2 \%$ to $52.8 \%$ ) times the risk for systolic blood pressure. In multivariate analysis, age, history of hypertension and pulse were not statistically significant (Table-IV).

Table-l: Demographic characteristics of the study patients $(n=100)$

\begin{tabular}{|c|c|c|c|c|c|c|c|}
\hline \multirow{3}{*}{$\begin{array}{l}\text { Demographic } \\
\text { characteristics }\end{array}$} & \multirow{3}{*}{ Total } & \multicolumn{4}{|c|}{$\begin{array}{c}\text { Systolic blood } \\
\text { pressure }\end{array}$} & \multirow{3}{*}{ OR (95\% Cl) } & \multirow{3}{*}{$p$ value } \\
\hline & & \multicolumn{2}{|c|}{$\begin{array}{l}\text { Normal } \\
(n=92)\end{array}$} & \multicolumn{2}{|c|}{$\begin{array}{l}\text { High } \\
(n=8)\end{array}$} & & \\
\hline & & $\mathrm{n}$ & $\%$ & $\mathrm{n}$ & $\%$ & & \\
\hline \multicolumn{8}{|l|}{ Age (years) } \\
\hline$<30$ & 70 & 67 & 95.7 & 3 & 4.3 & \multirow{2}{*}{$4.47(1.0-25.9)$} & \multirow{2}{*}{0.049} \\
\hline$\geq 30$ & 30 & 25 & 83.3 & 5 & 16.7 & & \\
\hline \multicolumn{8}{|l|}{$\begin{array}{l}\text { Hematocrit } \\
(\%)\end{array}$} \\
\hline$\leq 48$ (Low) & 95 & 87 & 91.6 & 8 & 8.4 & \multirow{2}{*}{$0.01(0.01-15.8)$} & \multirow{2}{*}{0.65} \\
\hline$>48$ (High) & 5 & 5 & 100.0 & 0 & 0.0 & & \\
\hline \multicolumn{8}{|c|}{ Pulse (beats per minute) } \\
\hline $60-80$ & 53 & 52 & 98.1 & 1 & 1.9 & \multirow{2}{*}{9.10 (1.1-99.9) } & \multirow{2}{*}{0.02} \\
\hline $81-100$ & 47 & 40 & 85.1 & 7 & 14.9 & & \\
\hline
\end{tabular}

Table-II: Factors exercise habits, eating habits and body mass index of the study patients $(n=100)$

\begin{tabular}{|c|c|c|c|c|c|c|c|}
\hline & \multirow{3}{*}{ Total } & \multicolumn{4}{|c|}{$\begin{array}{l}\text { Systolic blood } \\
\text { pressure }\end{array}$} & \multirow{3}{*}{ OR $(95 \% \mathrm{Cl})$} & \multirow{3}{*}{$\begin{array}{c}p \\
\text { value }\end{array}$} \\
\hline & & \multicolumn{2}{|c|}{$\begin{array}{l}\text { Normal } \\
(n=92)\end{array}$} & \multicolumn{2}{|c|}{$\begin{array}{l}\text { High } \\
(n=8)\end{array}$} & & \\
\hline & & $\mathrm{n}$ & $\%$ & $\mathrm{n}$ & $\%$ & & \\
\hline \multicolumn{8}{|l|}{ Exercise } \\
\hline Appropriate & 32 & 30 & 93.8 & 2 & 6.3 & $1.5(0.2-11.1)$ & 0.49 \\
\hline Inappropriate & 65 & 59 & 90.8 & 6 & 9.2 & $0.6(0.08-3.6)$ & 0.42 \\
\hline Never & 3 & 3 & 100.0 & 0 & 0.0 & - & 0.77 \\
\hline \multicolumn{8}{|l|}{ Fast food } \\
\hline 1-2 times/week & 55 & 51 & 92.7 & 4 & 7.3 & $1.2(0.2-6.4)$ & 0.52 \\
\hline 3-4 times/week & 37 & 35 & 94.6 & 2 & 5.4 & $1.8(0.3-14.5)$ & 0.37 \\
\hline Almost everyday & 8 & 6 & 75.0 & 2 & 25.0 & $0.2(0.03-1.9)$ & 0.12 \\
\hline \multicolumn{8}{|l|}{$\begin{array}{l}\text { Body mass index } \\
(\mathrm{kg} / \mathrm{m} 2)\end{array}$} \\
\hline $\begin{array}{l}18.5-24.9 \\
\text { (Normal) }\end{array}$ & 59 & 55 & 93.2 & 4 & 6.8 & $1.5(0.3-7.7)$ & 0.43 \\
\hline \begin{tabular}{|l|}
$\begin{array}{l}25.0-29.9 \text { (Over } \\
\text { weight) }\end{array}$ \\
\end{tabular} & 30 & 28 & 93.3 & 2 & 6.7 & $1.3(0.2-1.0)$ & 0.55 \\
\hline$\geq 30.0$ (Obese) & 11 & 9 & 81.8 & 2 & 18.2 & $0.3(0.05-2.7)$ & 0.21 \\
\hline
\end{tabular}

Table-III: Past medical and family history of hypertension $(n=100)$

\begin{tabular}{|c|c|c|c|c|c|c|c|}
\hline & \multirow{3}{*}{ Total } & \multicolumn{4}{|c|}{ Systolic blood pressure } & \multirow{3}{*}{ OR $(95 \% \mathrm{Cl})$} & \multirow{3}{*}{$\begin{array}{c}\mathrm{p} \\
\text { value }\end{array}$} \\
\hline & & \multicolumn{2}{|c|}{$\begin{array}{c}\text { Normal } \\
(n=92)\end{array}$} & \multicolumn{2}{|c|}{$\begin{array}{l}\text { High } \\
(n=8)\end{array}$} & & \\
\hline & & $n$ & $\%$ & $\mathrm{n}$ & $\%$ & & \\
\hline \multicolumn{8}{|c|}{$\begin{array}{l}\text { History of } \\
\text { hypertension }\end{array}$} \\
\hline Yes & 2 & 0 & 0.0 & 2 & 100.0 & \multirow{2}{*}{$0.01(0.02-0.33)$} & \multirow{2}{*}{0.006} \\
\hline No & 98 & 92 & 93.9 & 6 & 6.1 & & \\
\hline \multicolumn{8}{|c|}{$\begin{array}{l}\text { Family history of } \\
\text { hypertension }\end{array}$} \\
\hline Yes & 6 & 4 & 66.7 & 2 & 33.3 & \multirow[b]{2}{*}{$0.14(0.02-1.34)$} & \multirow{2}{*}{0.071} \\
\hline No & 94 & 88 & 93.6 & 6 & 6.4 & & \\
\hline
\end{tabular}

Table-IV: Multivariate regression analysis for systolic blood pressure

\begin{tabular}{|l|c|c|c|c|}
\hline & Adjusted & \multicolumn{2}{|c|}{$95 \% \mathrm{Cl}$} & \multirow{2}{*}{$\begin{array}{c}\mathbf{p} \\
\text { value }\end{array}$} \\
\hline & OR & Lower & Upper & 0.410 \\
\hline Age ( $\geq 30$ years) & 2.512 & 0.281 & 22.412 & 0.099 \\
\hline $\begin{array}{l}\text { History of } \\
\text { hypertension }\end{array}$ & 1.680 & 0.010 & 46.253 & 0999 \\
\hline $\begin{array}{l}\text { Pulse (>80 beats per } \\
\text { minute) }\end{array}$ & 3.500 & 0.232 & 52.796 & 0.366 \\
\hline
\end{tabular}

\section{Discussion}

In this study observed seventy patients belonged to age $<30$ years among them 67(95.7\%) in normal systolic blood pressure and $3(4.3 \%)$ in high systolic blood pressure. Fifty three patients were found pulse $60-80$ beats per minute among them $52(98.1 \%)$ in normal systolic blood pressure and 1(1.9\%) in high systolic blood pressure. Which were statistically significant $(p<0.05)$ between two groups. In study of Afian et al ${ }^{8}$ reported the 19-39 year old respondents, high SBP were more in older subjects. Comparison with pulse 60-80 times per minute, respondent's greater risk of suffering from high SBP they have higher pulse rate. While the universal blood vessel sensors would enhance the production 
of hypoxia-inducible factor 1 (HIF1) which mediated vascular endothelial factor 1 (VEGF1) to initiated the angiogenesis so that blood volume greater than before and high SBP might occur?. Moreover to hypoxia, cosmic radiation was one of the physiological environments in the aviation world. Accretion of cosmic radiation by elevated total flight hours, the dose of radiation exposure would be increased. This condition would increase lipogenesis and inhibit the lipolysis ${ }^{10}$. Therefore $\mathrm{NaCl}$ reabsorption would raise and SBP might occur ${ }^{11}$. Platsas et al ${ }^{12}$ reported mean SBP was positively and significantly associated with age ( $r s=0.191, p<0.01)$.

In this study, it was observed that 65 patients were inappropriately exercising. Among them, 59(90.8\%) in normal systolic blood pressure and 6(9.2\%) in high systolic blood pressure. Fifty five patients were eating fast food 1-2 times/week among them $51(92.7 \%)$ in normal systolic blood pressure and $4(7.3 \%)$ in high systolic blood pressure. Fifty nine patients had normal BMI among them 55(93.2\%) in normal systolic blood pressure and $4(6.8 \%)$ in high systolic blood pressure. The difference were not statistically significant $(p>0.05)$ between two groups. Afian et a $\left.\right|^{8}$ reported respondents who infrequently eat fast food (hardly ever 1-2 times per week), respondents who frequently consume fast food (almost every day) were more suffering from high SBP. Platsas et al ${ }^{12}$ observed that exercising for the mean period of $12.0 \pm 7.6$ years and most of them $(62.1 \%)$ favored exercising outside in contrast to indoors prearranged gyms (37.9\%). They also reported mean SBP was positively and significantly associated with mean body mass index ( $r s=0.205, p<0.01$ ). Dissimilar observation was found Siagian study they reported the percentage of overweight and obese pilots, were relatively high $25 \%$ and $68.8 \%$, respectively, in the group with high systolic blood pressure ${ }^{13}$.

Two patients had history of hypertension among them 2(100.0\%) in high systolic blood pressure. Which was statistically significant $(p<0.05)$ between two groups. Afian et al reported there were no differences between respondents with high and normal SBP in the matter of family history of hypertension. Additionally, when compared with respondents who did not have hypertension, respondents with a history of a better likelihood of high SBP.

In present study showed patients having age ( $\geq 30$ years) 2.512 $(95 \% \mathrm{Cl} 0.281 \%$ to $22.412 \%)$ times the risk for systolic blood pressure. Patients having history of hypertension $1.680(95 \% \mathrm{Cl}$ $0.010 \%$ to $46.253 \%$ ) times the risk for systolic blood pressure. Patients having Pulse (>80 beats per minute) $3.500(95 \% \mathrm{Cl}$ $0.232 \%$ to $52.796 \%$ ) times the risk for systolic blood pressure. In multivariate analysis, age, history of hypertension and pulse were not statistically significant. Afian et al reported age and history of hypertension were the two dominant risk factors that influence the incidence of high SBP. Compared with respondents aged 19-39 years, subject aged of 40-65 years had a risk of 15.1 times greater risk of high SBP $(p=0.001)$. In comparison with no history of hypertension and respondent history of hypertension having 93.2 times greater risk of high SBP $(p=0.001)$. SBP also affected by history of hypertension. In study of United States were indicating that the subject of old age who had not received treatment and had received treatment but did not suitable, would suffer from high $\mathrm{SBP}^{14}$ at $\mathrm{p}=0.0001$. Siagian $\mathrm{M}^{13}$ observed those who had high than normal resting pulse rate had 2.4 times to be high systolic blood pressure $(\mathrm{ORa}=2.37 ; 95 \mathrm{Cl}=0.8-6.9 ; \mathrm{P}=0.12)$.

Tomei et al ${ }^{15}$ showed that flight hours were associated with SBP $(r s=0.2, p<0.01)$. They reported strong relations between flight hours and both systolic and diastolic BP (group A-turboprop planes-systolic BP: $r=0.97, p=0.003$, diastolic $B P: r=0.98, p=0.003$ ) (group B-jet planes-systolic BP: $r=0.86, p=0.025$; diastolic BP: $r=0.76, p=0.005)$. They didn't find any association between flight hours and ECG abnormalities.

\section{Conclusion}

Consequently ,the excellent physical, mental \& psychological condition of pilots is practically synonymous to the positive outcome of each flight. Most of the air crew in Bangladesh Air force' Blood Pressure principles were all within normal range. Their observation suggested is encouraging and may reflect BAF crew' Uninterrupted efforts to maintain a healthful living. Few of BP values have been reported in the study history of hypertension they have also family history of Hypertension. On the other hand, there were some overweight and taken fast food while, few reported not exercising.

\section{References}

1. Platsas G, Kourianidis G, Toutouzas P et al. Parameters Associated with Elevated Systolic Blood Pressure Levels in Greek Military Pilots. The Open Hypertension Journal. 2014; 6:27-31.

2. Johnson MC, Banaag AL, Condie KJ et al. New ACC/AHA blood pressure guidelines and the operational readiness of Naval aviators and aircrew. Aerosp Med Hum Perform. 2019; 90(4):409-14.

3. Nicol ED, Manen $\mathrm{O}$, Guettler $\mathrm{N}$ et al. Congenital heart disease in aircrew. Heart. 2019; 105:s64-s69.

4. Silverman D, Gendreau M. Medical issues associated with commercial flights. Lancet. 2009; 373:2067-77.

5. Mieske K, Flaherty G, O'Brien T. Journeys to high altitude-Risks and recommendations for travelers with pre-existing medical conditions. J Travel Med. 2009; 17:48-62.

6. Grossman A, Wand O, Harpaz D et al. Acceleration forces and cardiac and aortic indexes in jet fighter pilots. Aviat Space Environ Med. 2011; 82:901-3.

7. Assa A, Prokupetz $A$, Wand $O$ et al. Echocardiographic evaluation and aortic indexes in aviators exposed to acceleration forces. J Am Soc Echocardiogr. 2011; 24:1163-7.

8. Afian F, Wangge G, Kaunang DRD. Total flying hours and risk of high systolic blood pressure in the civilian pilot in Indonesia. Health Science Journal of Indonesia. 2016; 7:54-8.

9. Hochachka PW. Mechanism and evolution of hypoxia-toler- 
ance in humans. J Exp Biol. 1998; 201:1243-54.

10. Mattson MPM. Roles of the lipid peroxidation product 4-hydroxynonenal in obesity, the metabolic syndrome, and associated vascular and neurodegenerative disorders. Exp Gerontol. 2009; 44:625-33.

11. Re RN. Obesity-related hypertension. J Ochsner. 2009; 9:133-6.

12. Platsas G, Kourianidis G, Toutouzas P et al. Parameters Associated with Elevated Systolic Blood Pressure Levels in Greek Military Pilots. The Open Hypertension Journal. 2014; 6:27-3.

13. Siagian M. Aircraft vibration and other factors related to high systolic blood pressure in Indonesian Air Force pilots. Health Science J Indonesia. 2012; 3:27-33.

14. Franklin SS, Jacobs MJ, Wong ND et al. Predominance of isolated systolic hypertension among middle-aged and elderly US hypertensives: Analysis based on National Health and Nutrition Examination Survey (NHANES) III. Hypertension. 2001; 37:869-74.

15. Tomei F, DeSio S, Tomao E et al. Occupational exposure to noise and hypertension in pilots. Int J Environ Health Res. 2005; 15:99-106. 